\title{
Adana ilinde TOPSIS yöntemi ile kuraklık analizi
}

\author{
Drought analysis by TOPSIS method in Adana
}

\section{Mete ÖZFIDANER ${ }^{1 \oplus}$, Engin GÖNEN ${ }^{1}$ i⿺, Sinan KARTAL ${ }^{2}$ [i]}

${ }^{1}$ Alata Bahçe Kültürleri Araştırma Enstitüsü Müdürlüğü

${ }^{2}$ Akdeniz Üniversitesi, Kumluca Meslek Yüksekokulu, Bitkisel ve Hayvansal Üretim Bölümü

Sorumlu yazar (Corresponding author): M. Özfidaner, e-posta (e-mail): mete.ozfidaner@tarimorman.gov.tr

Yazar(lar) e-posta (Author e-mail): engin.gonen@tarimorman.gov.tr, skartalguray@hotmail.com

\section{MAKALE BILLGISİ}

Alınıs tarihi 04 Kasım 2019

Düzeltilme tarihi 02 Ocak 2020

Kabul tarihi 16 Ocak 2020

\section{Anahtar Kelimeler:}

Kuraklık

TOPSIS

Adana

\begin{abstract}
ÖZ
Adana ilinde 1963-2016 yılları arasında yıllık buharlaşma, maksimum ve minimum sıcaklık ve toplam yağış verileri kullanılarak kurak veya yağışlı geçen yılların hesaplanması amaçlanmıştır. Yapılan çalıșmada verileri üretmek için TOPSIS yöntemi seçilmiş ve bu yönde bir model oluşturulmuştur. Bu amaç için bölgede en uzun yağış, sıcaklık ve buharlaşma kayıtlarına sahip olan Adana Meteoroloji İstasyonuna ilişkin veriler kullanılmıştır. Çalışma sonucunda 54 yılda, 10 defa orta, 15 defa zayıf ve 7 defa ciddi kurak yıl belirlenmiștir. Ciddi kuraklık yașanan y1llar 1970-1973, 1982, 1986 ve 1993 yılları olarak tespit edilmiştir. Son 10 yılda 5 yıl kurak olarak geçmiștir. Kurak geçen yıllar ise 2007, 2008, 2010, 2013 ve 2014 yılları olarak bulunmuștur.
\end{abstract}

\section{ARTICLE INFO}

Received 04 November 2019

Received in revised form 02 January 2020

Accepted 16 January 2020

\section{Keywords:}

Drought

TOPSIS

Adana

\begin{abstract}
It is aimed to calculate the years of dry or rainy years in Adana by using the annual evaporation, maximum and minimum temperature and total precipitation data between 1963-2016. In the study, TOPSIS method was selected to produce the data and a model was created in this direction. For this purpose, data related to Adana Meteorological Station which has the longest precipitation, temperature and evaporation records in the region was used. At the end of the study, 10 times medium, 15 times weak and 7 times severe dry years were determined. The years of severe drought were determined as 1970-1973, 1982, 1986 and 1993 The last 10 years have been 5 years dry. The dry years were found to be 2007, 2008, 2010, 2013 and 2014.
\end{abstract}

\section{Giriş}

Kuraklık ekoloji için acil durum olarak bilinir ve meteorologlar, hidrologlar, jeologlar, ekolojistler ve tarım mühendisleri kuraklık ile ilgilenirler. Neredeyse tüm iklim bölgelerinde yüksek hem de düşük yağış alan bölgelerde kuraklıklar görülebilir. Kuraklık bir yıl veya bir mevsim gibi yağış hacmindeki uzun süreli düşüşe büyük ölçüde bağlıdır. Ayrıca, yağışlar, sıcaklıklar, zamanlama ve özellikleri, düşük bağıl nem, yüksek rüzgarlar, mahsul yetiştirme dönemlerinde 1slak dönemlerin sayılması, yağmur süresi ve yoğunluğu ve kuraklıkta başlangıç ve bitiş önemli bir rol oynar (Mishra ve Singh 2011).

Kuraklık meteorolojik olarak geçici ve sık görülen, uzun zaman aralıklarında azalan yağıştan kaynaklanan bir olaydır. Kuraklıklar, herhangi bir iklimin normal fenomenleridir ve en karmaşık doğal tehlike olabilirler ve yavaş yavaş geliştikleri için, tahmin edilmesi zor ve herhangi bir alanda geniş bir etki spektrumuna sahiptirler (Morid ve ark. 2007). Kuraklığa hazır olma ve azaltma etkinliği, büyük ölçüde, kuraklığın başlangıcına, zamana ve mekansal derecede genişlemeye ilişkin zamanında verilere bağlıdır. Bu bilgi, normalde kuraklık dizinleri kullanılarak yapılan sürekli kuraklık izlemesi ile elde edilebilir. Kuraklık dizinleri sürekli yağış ile ilişkili olmakla beraber buharlaşma ve sıcaklıkta bu ilişki içindedir (Morid ve ark. 2007). Son otuz yılda, kuraklığın sıklığında ve şiddetinde artma görünmüştür (Hulme ve Kelly 1993; Mccarthy ve ark. 2001). Kurak mevsim eğilimi, su krizlerinin dünyanın çeşitli bölgelerinde yaşanmasına neden olmuştur (Dai ve ark. 2004; Ghulam ve ark. 2008). Bunun nedeni, su kaynaklarında meydana gelen düşüş ve bu nedenle tarımsal, ekonomik ve sosyal olaylar üzerinde önemli etkileri olduğu gerçeğidir (Riebsame ve ark. 1991).

Dünya ve ülkemizde bugüne kadar çeşitli amaçlara yönelik olarak kuraklık araştırmaları yapılmıştır. Genelde kuraklık olayına araştırmacılar kendi uzmanlıkları açısından yaklaşmışlardır. Bunlardan; (Kemali ve Nikzad 1990; Rostemi 1997) tarımsal kuraklık, (Türkeş 1990; Özkan 2001; Fereczadeh 
2001; Türkeş 2002; Sırdaş 2002; Sırdaş ve Şen 2003; Pamuk ve ark. 2004; Özfidaner 2007; Edossa ve ark. 2009; Türkeş ve Tatlı 2009), meteorolojik kuraklık ve (Erdoğan 1989; Siyadeti ve Ensari 2001; Köse ve Dorum 2002; Topaloğlu 2006a, b; Nalbantis ve Tsakiris 2009; Yürekli ve ark. 2009; Kıymaz ve ark. 2011; Topaloğlu ve ark. 2012; Tigkas ve ark. 2012; Tabari ve ark. 2012; Arabzadeh ve ark. 2015; Özfidaner ve ark. 2018) ise hidrolojik kuraklık konularında çalışmalar yapmışlardır.

Son yıllarda, mantıklı bir yaklaşım tarzı nedeniyle, TOPSIS birçok problemini çözmek için kullanılmıştır (Shih ve ark. 2007). TOPSIS, konum araştırmasında (Yoon ve Hwang 1985) çok amaçlı karar verme (Lai 1994), toplu karar verme (Shih ve ark. 2001), ürün tasarımı (Kwong ve Tam 2002), ulaştırma (Janic 2003), insan kaynakları yönetimi (Chen ve Tzeng 2004), su yönetimi (Srdjevic ve ark. 2004), üretim (Milani ve Shanian 2005) ve kalite kontrolü (Yang ve Chou 2005) konularında kullanılan bir yöntemdir.

Kazemi ve ark. (2012) İran'ın Gilan eyaletinin kuraklığında kullanılan TOPSIS yöntemi ile kuraklığın belirlenmesinde ve sıralanmasında etkili olarak değişen yıllardaki hava durumu değerleri arasındaki metodik bağlantıyı göstermiştir. Bu tekniği sadece bir veya iki parametre kullanan farklı mütevazı yaklaşımlardan daha etkili kılan 9 iklim parametresi uygulanmaktadır. Bu tekniğin bir başka özelliği de kuraklığı sıraya koymaktır. Sepehr ve Zucca (2012), TOPSIS'i, üç farklı ülkede (Brezilya, Mozambik ve Portekiz) çölleşme göstergelerinin seçimi ve dahil edilmesi için karar verme tekniği olarak kullanmışlardır. Tanrıverdi ve ark. (2018) Kahramanmaraş'ta yaptıkları çalışmada TOPSIS'i 5 farklı meteorolojik parametre kullanarak uygulamışlardır.

$\mathrm{Bu}$ çalışmanın amacı Adana meteoroloji istasyonundan temin edilen yıllık buharlaşma, maksimum ve minimum sıcaklık ve toplam yağış veriler ile oluşturulan TOPSIS modeli ile 1963-2016 yılları arasındaki meydana gelen kuraklıkları ve kuraklık şiddetlerini belirlemektir.

\section{Materyal ve Metot}

\subsection{Materyal}

$\mathrm{Bu}$ çalışmada, Adana (17351) Meteoroloji İstasyonunda 1963-2016 yılları arasında geçen sürede ölçülen yıllık ortalama maksimum, minimum sıcaklık, toplam yağış ve buharlaşma verileri kullanılmıştır. $\mathrm{Bu}$ değerler Meteoroloji İşleri Genel Müdürlüğünden elde edilmiştir.

\subsection{Metot}

TOPSIS (Çok Kriterli Karar Verme Yöntemi) 1980 yılında Yoon ve Hwang tarafindan geliştirilmiştir. Karar noktalarının ideal çözüme yakınlığı ana prensibine dayanır. TOPSIS yöntemi 6 başlıkta oluşan bir çözüm sürecini içerir. Bu başlıklar aşağıda belirtilmiştir.

Başlık 1: Karar matrisinin (A) oluşturulması

Başlık 2: Standart Karar Matrisinin (R) Oluşturulması

Başlık 3: Ağırlıklı standart karar matrisinin (V) oluşturulması

Başlık 4: İdeal $\left(\mathrm{A}^{*}\right)$ ve negatif ideal $\left(\mathrm{A}^{-}\right)$çözümlerin oluşturulması

Başlık 5: Ayırım ölçülerinin hesaplanması

Başlık 6: İdeal çözüme göreli yakınlığın hesaplanması

\subsubsection{Karar matrisinin oluşturulmas}

Karar matrisinin satırlarında üstünlükleri sıralanmak istenen karar noktaları, sütunlarında ise karar vermede kullanılacak değerlendirme faktörleri yer alır. A matrisi karar verici tarafindan oluşturulan başlangıç matrisidir. Karar matrisi Eşitlik 1' de verilmiştir:

$$
A_{i j}=\left[\begin{array}{cccc}
a_{11} & a_{12} & \ldots & a_{1 n} \\
a_{21} & a_{22} & \ldots & a_{2 n} \\
\cdot & & & \cdot \\
\cdot & & & \cdot \\
\cdot & & & \cdot \\
a_{m 1} & a_{m 2} & \ldots & a_{m n}
\end{array}\right]
$$

Aij matrisinde m karar noktası sayısını, n değerlendirme faktörü sayısını verir.

\subsubsection{Standart karar matrisinin (R) oluşturulması}

Standart Karar Matrisi, A matrisinin elemanlarından yararlanarak ve Eşitlik 2 kullanılarak hesaplanır.

$$
r_{i j}=\frac{a_{i j}}{\sqrt{\sum_{k=1}^{m} a_{k j}^{2}}}
$$

R matrisi aşağıdaki Eşitlik 3' deki gibi elde edilir:

$$
R_{i j}=\left[\begin{array}{cccc}
r_{11} & r_{12} & \ldots & r_{1 n} \\
r_{21} & r_{22} & \ldots & r_{2 n} \\
\cdot & & & \cdot \\
\cdot & & & \cdot \\
\cdot & & & \cdot \\
r_{m 1} & r_{m 2} & \ldots & r_{m n}
\end{array}\right]
$$

\subsubsection{Ağırlıklı standart karar matrisinin (V) oluşturulması}

Öncelikle değerlendirme faktörlerine ilişkin ağırlık değerleri eşitlik 4 ile $\left(\mathrm{w}_{\mathrm{i}}\right)$ belirlenir.

$$
\sum_{i=1}^{n} w_{i}=1
$$

Daha sonra $\mathrm{R}$ matrisinin her bir sütunundaki elemanlar ilgili değeri ile çarpılarak V matrisi oluşturulur. V matrisi Eşitlik 5'de gösterilmiştir:

$$
V_{i j}=\left[\begin{array}{cccc}
w_{1} r_{11} & w_{2} r_{12} & \ldots & w_{n} r_{1 n} \\
w_{1} r_{21} & w_{2} r_{22} & \ldots & w_{n} r_{2 n} \\
\cdot & & & \cdot \\
\cdot & & & \cdot \\
\cdot & & & \cdot \\
w_{1} r_{m 1} & w_{2} r_{m 2} & \ldots & w_{n} r_{m n}
\end{array}\right]
$$




\subsection{4. İdeal $\left(A^{*}\right)$ ve negatif ideal $\left(A^{-}\right)$çözümlerin oluşturulması}

TOPSIS yöntemi, her bir değerlendirme faktörünün monoton artan veya azalan bir eğilime sahip olduğunu varsaymaktadır. İdeal çözüm setinin oluşturulabilmesi için $\mathrm{V}$ matrisindeki ağırlıklandırılmış değerlendirme faktörlerinin yani sütun değerlerinin en büyükleri (ilgili değerlendirme faktörü minimizasyon yönlü ise en küçüğü) seçilir. İdeal çözüm setinin bulunması aşağıdaki Eşitlik 6' da gösterilmiştir.

$$
A^{*}=\left\{\left(\max _{i} v_{i j} \mid j \in J\right),\left(\min _{i} v_{i j} \mid j \in J^{\prime}\right\}\right.
$$

formülünden hesaplanacak set şeklinde gösterilebilir.

Negatif ideal çözüm seti ise, $\mathrm{V}$ matrisindeki ağırlıklandırılmış değerlendirme faktörlerinin yani sütun değerlerinin en küçükleri (ilgili değerlendirme faktörü maksimizasyon yönlü ise en büyüğü) seçilerek oluşturulur. Negatif ideal çözüm setinin bulunması aşağıdaki Eşitlik 7'de gösterilmiştir.

$$
A^{-}=\left\{\left(\min _{i} v_{i j} \mid j \in J\right),\left(\max _{i} v_{i j} \mid j \in J^{\prime}\right\}\right.
$$

formülünden hesaplanacak set şeklinde gösterilebilir.

Her iki formülde de fayda (maksimizasyon), ise kayıp (minimizasyon) değerini göstermektedir. Gerek ideal gerekse negatif ideal çözüm seti, değerlendirme faktörü sayısı yani $\mathrm{m}$ elemandan oluşmaktadır.

\subsubsection{Ayırım ölçülerinin hesaplanması}

TOPSIS yönteminde her bir karar noktasına ilişkin değerlendirme faktör değerinin İdeal ve negatif ideal çözüm setinden sapmalarının bulunabilmesi için Euclidian Uzaklık Yaklaşımından yararlanılmaktadır. Buradan elde edilen karar noktalarına ilişkin sapma değerleri ise İdeal Ayırım $\left(\mathrm{S}_{\mathrm{i}}{ }^{*}\right)$ ve Negatif İdeal Ayırım $\left(\mathrm{S}_{\mathrm{i}}^{-}\right)$Ölçüsü olarak adlandırılmaktadır. İdeal ayırım $\left(\mathrm{S}_{\mathrm{i}}^{*}\right)$ ölçüsünün hesaplanması Eşitlik 8'de, negatif ideal ayırım $\left(\mathrm{S}_{\mathrm{i}}^{-}\right)$ölçüsünün hesaplanması ise Eşitlik 9'da gösterilmiştir.

$$
\begin{array}{ll}
S_{i}^{*} & =\sqrt{\sum_{j=1}^{n}\left(v_{i j}-v_{j}^{*}\right)^{2}} \\
S_{i}^{-} & =\sqrt{\sum_{j=1}^{n}\left(v_{i j}-v_{j}^{-}\right)^{2}} \\
\mathrm{i}=1,2, \ldots, \mathrm{m}
\end{array}
$$

Burada hesaplanacak ve sayısı doğal olarak karar noktası sayısı kadar olacaktır.

\subsection{6. İdeal çözüme göreli yakınlı̆̆ın hesaplanması}

Her bir karar noktasının ideal çözüme göreli yakınlığının $\left(\mathrm{C}_{\mathrm{i}}{ }^{*}\right)$ hesaplanmasında ideal ve negatif ideal ayırım ölçülerinden yararlanılır. Burada kullanılan ölçüt, negatif ideal ayırım ölçüsünün toplam ayırım ölçüsü içindeki payıdır. İdeal çözüme göreli yakınlık değerinin hesaplanması aşağıdaki Eşitlik 10'da gösterilmiştir.

$$
C_{i}^{*}=\frac{S_{i}^{-}}{S_{i}^{-}+S_{i}^{*}} \quad \mathrm{i}=1,2, \ldots, \mathrm{m}
$$

Burada $\mathrm{C}_{\mathrm{i}}{ }^{*}$ değeri $0 \leq C_{i}^{*} \leq 1$ aralığında değer alır ve $\mathrm{C}_{\mathrm{i}}^{*=1}$ ilgili karar noktasının ideal çözüme, $C_{i}^{*}=0$ ilgili karar noktasının negatif ideal çözüme mutlak yakınlığını gösterir.

\subsubsection{TOPSIS kuraklık analizinde belirleyici $C^{*}$ katsayı değer anlamı}

Elde edilen TOPSİS kuraklık değerlerine ait kurak ve islak sınıf değerleri Çizelge 1'de verilmiştir. Toplam 9 adet sınıf değeri belirlenmiş olup bu değerler 0 ile 1 arasında değer almaktadır. Kurak sınıf değerleri 0-0.3 değerleri arasında belirlenmiștir.

Çizelge 1. TOPSIS metodu sinıf değerleri.

Table 1. TOPSIS method class values.

\begin{tabular}{cccc}
\hline Kuraklık Sınıfi & \multicolumn{3}{c}{ Kuraklık Değerleri } \\
\hline Son Derece Islak & 0.9 & $<$ TOPSIS $<$ & 1 \\
Ciddi Islak & 0.8 & $<$ TOPSIS $<$ & 0.9 \\
Orta Islak & 0.7 & $<$ TOPSIS $<$ & 0.8 \\
Zayıf Islak & 0.6 & $<$ TOPSIS $<$ & 0.7 \\
Normal & 0.4 & $<$ TOPSIS $<$ & 0.6 \\
Zayıf Kurak & 0.3 & $<$ TOPSIS $<$ & 0.4 \\
Orta Kurak & 0.2 & $<$ TOPSIS $<$ & 0.3 \\
Ciddi Kurak & 0.1 & $<$ TOPSIS $<$ & 0.2 \\
Son Derece Kurak & & TOPSIS $<$ & 0 \\
\hline
\end{tabular}

\section{Bulgular ve Tartıșma}

Adana ilinde bulunan 17351 nolu Meteoroloji istasyonundan alınan yıllık ortalama maksimum, minimum sıcaklık, toplam yağış, buharlaşma verileri ile yapılan TOPSIS kuraklık sonuçları Şekil 1'de ve kuraklık sınıf değerleri ise Çizelge 2'de verilmiştir.

Şekil 1'de görüleceği gibi Adana istasyonunda genel olarak kuraklık görülmüsstür. İncelenen 1963-2016 yılları arasında C değerleri bakımından kurak geçen yıl sayısı 32 (\%60) adet belirlenmiştir. Belirlenen kuraklık değerlerini sınıflandırdığımız zaman \%46.9 (15adet) ile zayıf kurak, \%31.2 (10 adet) ile orta kurak ve \%21.9 (7 adet) ile ciddi kurak y1l belirlenmiștir. Normal geçen y1l sayısı ise $16(\% 30)$ adet ve sslak dönemler ise $6(\% 10)$ adet olarak belirlenmiştir.

Çizelge incelendiği zaman ciddi kuraklık gösteren yıllar 1970-1973, 1982, 1986, 1993 y1llarında, orta kuraklık 1964, 1975, 1979, 1984, 1989, 1990, 1999, 2002, 2005, 2008 yıllarında görülmüştür. Tanrıverdi ve ark. (2018) Kahramanmaraş'ta TOPSIS ile yaptıkları çalışmada 2002, 2008 ve 2011 yıllarında kuraklık olduğunu tespit etmişlerdir. Orta kuraklık dönemler 1999 yılından önce 4 ve 5 yılda bir görülür iken, 1999 yılından sonra 3 yıl ara ile görülmeye başlanmıştır. Zayıf kuraklık gösteren yıllar incelendiği zaman 1996 yılından sonra kurak gecen yıl sayısın da artma görülmüştür. 1963-1995 y1lına kadar sadece 4 yıl zayıf kurak geçer iken, 1996-2016 yılında 11 yıl zayıf kurak geçmiştir. Zayıf kurak geçen 11 yıl incelendiği zaman ortalama 2-3 yılda bir kuraklık olduğu görülmektedir. 1996-1998 yılları arasında ortaya çıkan 3 yıllık zayıf kuraklık döneminden sonra 1 yıl orta kurak meydana gelmiş daha sonra tekrar zayıf kurak (2000) yıl ortaya çıkmıştır. 2000 yılından sonra 3 yil ara ile zayıf kurak yıllar meydana 


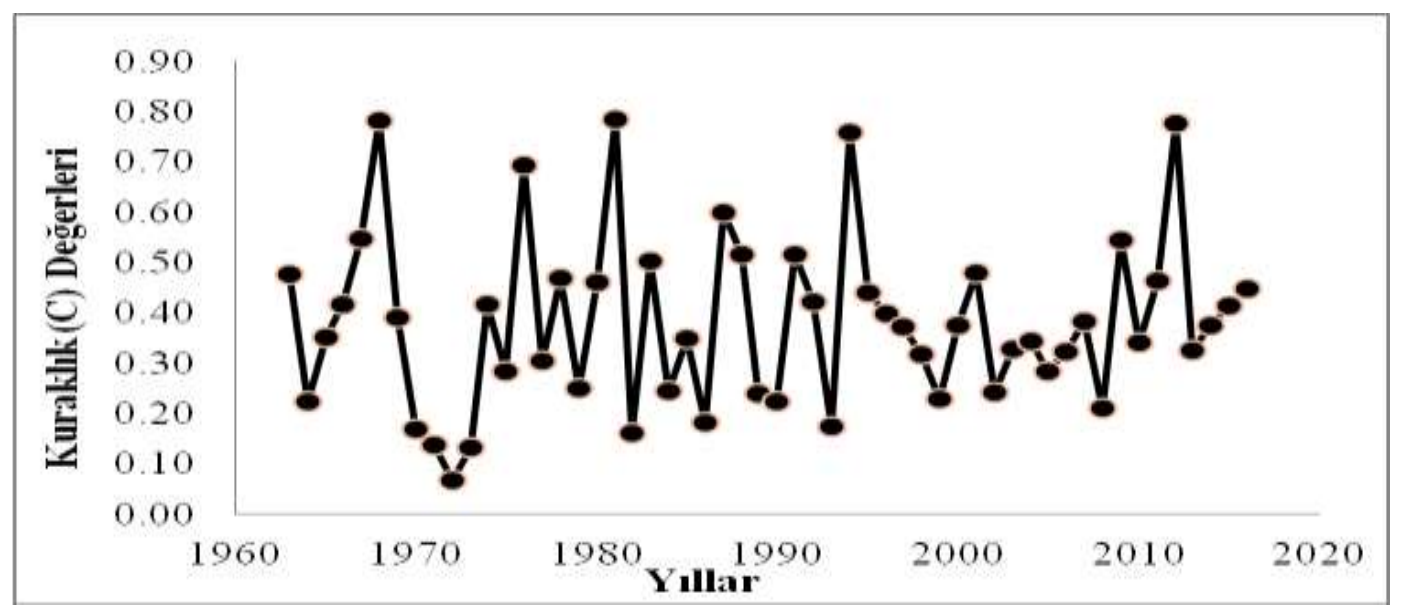

Şekil 1 Yıllara göre TOPSIS C değerleri.

Figure1. TOPSIS $\mathrm{C}$ values by years.

Çizelge 2. Adana meteoroloji istasyonu TOPSIS sonuçları.

Table2. Adana meteorological station TOPSIS results.

\begin{tabular}{|c|c|c|c|c|c|}
\hline Yillar & $\mathrm{C}$ değeri & Kuraklık Sınıfı & Yillar & $\mathrm{C}$ değeri & Kuraklık Sinıfı \\
\hline 1963 & 0.48 & Normal & 1990 & 0.22 & Orta Kurak \\
\hline 1964 & 0.22 & Orta Kurak & 1991 & 0.52 & Normal \\
\hline 1965 & 0.35 & Zayıf Kurak & 1992 & 0.42 & Normal \\
\hline 1966 & 0.42 & Normal & 1993 & 0.17 & Ciddi Kurak \\
\hline 1967 & 0.55 & Normal & 1994 & 0.76 & Orta Islak \\
\hline 1968 & 0.78 & Orta Islak & 1995 & 0.44 & Normal \\
\hline 1969 & 0.39 & Zayıf Kurak & 1996 & 0.397 & Zayıf Kurak \\
\hline 1970 & 0.17 & Ciddi Kurak & 1997 & 0.37 & Zayıf Kurak \\
\hline 1971 & 0.14 & Ciddi Kurak & 1998 & 0.32 & Zayıf Kurak \\
\hline 1972 & 0.07 & Ciddi Kurak & 1999 & 0.23 & Orta Kurak \\
\hline 1973 & 0.13 & Ciddi Kurak & 2000 & 0.37 & Zayıf Kurak \\
\hline 1974 & 0.42 & Normal & 2001 & 0.48 & Normal \\
\hline 1975 & 0.28 & Orta Kurak & 2002 & 0.24 & Orta Kurak \\
\hline 1976 & 0.69 & Zayıf Islak & 2003 & 0.33 & Zayıf Kurak \\
\hline 1977 & 0.31 & Zayıf Kurak & 2004 & 0.34 & Zayıf Kurak \\
\hline 1978 & 0.47 & Normal & 2005 & 0.28 & Orta Kurak \\
\hline 1979 & 0.25 & Orta Kurak & 2006 & 0.32 & Zayıf Kurak \\
\hline 1980 & 0.46 & Normal & 2007 & 0.38 & Zayıf Kurak \\
\hline 1981 & 0.78 & Orta Islak & 2008 & 0.21 & Orta Kurak \\
\hline 1982 & 0.16 & Ciddi Kurak & 2009 & 0.54 & Normal \\
\hline 1983 & 0.50 & Normal & 2010 & 0.34 & Zayıf Kurak \\
\hline 1984 & 0.24 & Orta Kurak & 2011 & 0.46 & Normal \\
\hline 1985 & 0.35 & Zayıf Kurak & 2012 & 0.78 & Orta Islak \\
\hline 1986 & 0.18 & Ciddi Kurak & 2013 & 0.33 & Zayıf Kurak \\
\hline 1987 & 0.6003 & Zayıf Islak & 2014 & 0.37 & Zayıf Kurak \\
\hline 1988 & 0.52 & Normal & 2015 & 0.41 & Normal \\
\hline 1989 & 0.24 & Orta Kurak & 2016 & 0.45 & Normal \\
\hline
\end{tabular}

gelmiştir. Boyacı ve ark. (2016) tarafindan Kırşehir ilinde yapılan çalışmada, uzun yıllar (1960-2015) ve son on yıllık sıcaklık ve bağıl nem değişimlerini inceledikleri çalışmalarında son 10 yılın yıllık periyotta ortalama sicaklık değerinin uzun yıllara göre $0.68^{\circ} \mathrm{C}$ daha yüksek, bağıl nemin ise $\% 2.96$ daha düşük olduğunu bildirmişlerdir. Yapılan çalışmada da benzer olarak artan sıcaklık değerlerinin Adana ilinde kuraklığın artmasına neden olduğu görülmüştür. Özfidaner ve ark. (2019a) Adana ilinde yaptıkları çalışmada, 1960-2018 yılları arasında maksimum ve minimum sicaklık değerlerinde y1llık bazda minimum sıcaklıklarda önemli artış, maksimum sıcaklıklarda ise önemsiz artma gidişleri tespit etmişlerdir. Bu çalışma da paralel olarak kuraklığın artmasının bir nedeni olarak görülebilir. Benzer sonuçlar Özfidaner ve ark. (2019b) Antalya ve Alanya istasyonları içinde bulunmuştur. Anılan Çalışmada Antalya istasyonu için y1llık $0.036^{\circ} \mathrm{C}$, Alanya istasyonu için ise $0.071^{\circ} \mathrm{C}$ artma olacağı belirlenmiş olup, kurak dönemlerin Adana istasyonunda da benzer kuraklığı etkileyeceği söz konusudur. Angın ve ark. (2019) Çukurova bölgesinde yaptıkları çalışmada, Adana istasyonuna ait uzun dönemli 
(1960-2018) yağış ve sıcaklık değerlerinde önemli artışların olduğunu ve kuraklığın ön plana çıktığını belirlemişlerdir. Bu sonuçlar ile yaptığımız çalışma sonuçları paralellik göstermektedir.

\section{Sonuçlar}

Elde edilen sonuçlardan uzun dönemler halinde hidrolojik, tarımsal ve sosyoekonomik kuraklığın etkilerini belirlemek ve bu etkilere göre çözümler üretmek gerekmektedir. Bölge açısından kuraklığın önemi tarımsal faaliyetlerin sonucunu doğrudan etkilemektedir. Kuraklık dönemlerinde ki artma eğilimi tarımsal faaliyetlerde kullanılan suyun önemini arttıracaktır. Sicaklıklarda olası artma eğilimi göstermesi ile beraber bölgede özellikle iklim değișikliğinin de etkisi ile kuraklığın su kullanımını sınırlayacağı bilinmelidir.

Adana bölgesi yarı kurak bir iklime sahip olması nedeni ile su kaynakları ile ilgili projelerinin hayata geçirilmesinde, bölgede meydana gelen kuraklığın şiddet ve süre etkilerinin göz önünde bulundurulması gerekmektedir. Özellikle kuraklık eğilimi görülen ayların ve yılların izlenmesi ve su kaynakları planlayıcılarının olası kuraklık için gerekli tedbirleri alması önem arz etmektedir.

\section{Kaynaklar}

Angın N, Çatalkaya V, Özfidaner M (2019) Trend analysis of meterological parameters in çukurova region. 6 th Congress on Soil and Water Resources with International Participation Abstract Book. 152.

Arabzadeh R, Kholoosi MM, Bazrafshan J (2015) Regional hydrological drought monitoring using principal components analysis. Journal of Irrigation and Drainage Engineering 142(1): 04015029.

Boyacı S, Akyüz A, Baytorun AN, Çaylı A (2016) Kırşehir ilinin örtü altı tarım potansiyelinin belirlenmesi. Nevşehir Bilim ve Teknoloji Dergisi Cilt 5(2): 142-157.

Chen MF, Tzeng GH (2004) Combining gray relation and TOPSIS concepts for selecting an expatriate host country. Mathematical and Computer Modelling 40: 1473-1490.

Dai A, Trenberth KE, Qian T (2004) A global data set of palmer drought severing index for 1870-2002: relationship with soil moisture and effects of surface warming. Journal of Hydrometeorology 5(6): 1117-1130.

Edossa DC, Babel MS, Das GA (2009) Drought analysis in the awash river basin, ethiopia. Water Resources Management 24(7): 14411460 .

Erdoğan F (1989) Türkiye'de yaygın kuraklık. Meteoroloji Mühendisleri Odası Bülteni 2: 1-4.

Fereczadeh M (2001) Kuraklık olayına karşı olan bazı yeni önlemler ve yöntemleri. Drought. FC. 777-786.

Ghulam A, Qin Q, Kusky TM, Li ZL (2008) A re-examination of perpendicular drought indices. Internatiol Journal Remote Sensing 29(20): 6037-6044.

Hulme M, Kelly M (1993) Exploring the links between desertification and climate change. Environment: Science and Policy for Sustainable Development 35(6): 4-45.

Janic M (2003) Multicriteria evaluation of high-speed rail, transrapid maglev, and air passenger transport in Europe. Transportation Planning and Technology 26: 491-512.

Kazemi LR, Ghamgosar M, Haghyghy M (2012) Multi criteria decision making based on TOPSIS method in drought zoning: A case study of gilan province. World Applied Programming Journal 2: 81-87.
Kemali K, Nikzad M (1990) Tarımsal kuraklıkla ilgili meteorolojik indeksler. Nivar pp. 9-19.

Kıymaz S, Güneş V, Aşar M (2011) Standartlaştırılmış yağış indeksi ile Seyfe gölünün kuraklık dönemlerinin belirlenmesi. Gaziosmanpaşa Üniversitesi Ziraat Fakültesi Dergisi 28(1): 91-102.

Köse Ö, Dorum A (2002) Orta Anadolu kapalı havzası kuraklık parametrelerinin olasılık dağılımı. Turkish Journal Engineering Environmental Sciences 26: 85-93.

Kwong CK, Tam SM (2002) Case-based reasoning approach to concurrent design of low power transformers. Journal of Materials Processing Technology 128: 136-141.

Lai YJ (1994) TOPSIS for MODM. European Journal of Operational Research 76: 486-500.

Mccarthy JJ, Canziani OF, Leary NA, Dokken DJ, White KS (2001) Climate change 2001 impacts, adaptation and vulnerability: Contribution of working Group II to the Third Assessment Report of the Intergovernmental Panel on Climate Change. Cambridge University Press, Cambridge.

Milani AS, Shanian A, Madoliat R (2005) The effect of normalization norms in multiple attribute decision making models a case study in gear material selection. Structural Multidisciplinary Optimization 29: 312-318.

Mishra AK, Singh VP (2011) Drought modeling - a review. Journal of Hydrology 403: 157-175.

Morid S, Smakhtin V, Bagherzadeh K (2007) Drought forecasting using artificial neural networks and time series of drought indices. International Journal of Climatology 27: 2103-2111.

Nalbantis I, Tsakiris G (2009) Assessment of hydrological drought revisited. Water Resource Management 23: 881-897.

Özfidaner M (2007) Türkiye yağış verilerinin trend analizi ve nehir akımları üzerine etkisi. Yüksek Lisans Tezi, Çukurova Üniversitesi Fen Bilimleri Enstitüsü, Adana.

Özfidaner M, Şapolyo D, Topaloğlu F (2018) Seyhan havzası akım verilerinin hidrolojik kuraklık analizi. Toprak Su Dergisi 7(1): 5764.

Özfidaner M, Şapolyo D, Topaloğlu F (2019a) Adana ilinde maksimum ve minimum sıcaklıkların gidiş analizi. Mediterranean Agriculture Sciences 32(2): 237-241.

Özfidaner M, Şapolyo UD, Topaloğlu F (2019b) Determination of the average temperature data: Antalya and Alanya case. Mustafa Kemal Üniversitesi Tarım Bilimleri Dergisi 20(Özel Sayı): 106-111.

Özkan K (2001) Eğirdir gölü havzası'nın kuraklık etüdü ve tarımormancılık açısından değerlendirmesi. Süleyman Demirel Üniversitesi. Orman Fakültesi Dergisi Seri: A, Say1 2: 75-96.

Pamuk G, Özgürel M, Topçuoğlu K (2004) Standart yă̆ış indisi (SYİ) ile ege bölgesinde kuraklık analizi. Ege Üniversitesi Ziraat Fakültesi Dergisi 41(1): 99-106.

Riebsame WE, Changnon SA, Karl TR (1991) Drought and natural resource management in the united states impacts and implications of the 1987-1989 drought. Dordrecht: Kluwer Academic Publishers.

Rostemi FF (1997) 1990’ın onluğunda kuraklık olayı. Bahar. İran, pp. 19-28.

Sepehr A, Zucca C (2012) Ranking desertification indicators using TOPSIS algorithm. Springer 62: 1137-1153.

Shih HS, Lin WY, Lee ES (2001) Group decision making for TOPSIS. Joint 9th IFSA World Congress and 20th NAFIPS International Conference, IFSA/NAFIPS 2001, 25-28 July, Vancouver, Canada, pp. 2712-2717.

Shih HS, Lin WY, Lee ES (2007) An extension of TOPSIS for group decision making. Mathematical and Computer Modeling 45: 801813 . 
Sirdas S (2002) Meteorolojik Kuraklık Modellemesi ve Türkiye Uygulamaları. Doktora Tezi, İstanbul Teknik Üniversitesi Fen Bilimleri Enstitüsü, İstanbul.

Sırdas S, Şen Z (2003) Meteorolojik kuraklık modellemesi ve Türkiye uygulaması. İstanbul Teknik Üniversitesi Dergisi/D Mühendislik 2(2): $95-103$

Siyadeti SB, Ensari J (2001) Erak çölünde yeraltı su kaynaklarına kuraklık olayının etkisi. Preceding of First National Conference on Drought Mitigation and Water Shortage, pp. 736-741.

Srdjevic B, Medeiros YDP, Faria AS (2004) An objective multi-criteria evaluation of water management scenarios. Water Resources Management 18: 35-54.

Tabari H, Abghari H, Talaee PH (2012) Temporal trends and spatial characteristics of drought and rainfall in arid and semiarid regions of Iran. Hydrological Proceses 26(22): 3351-3361.

Tanrıverdi Ç, Değirmenci H, Tekinerdoğan M, Gönen E, Arslan F, Atilgan A (2018) Precision of drought based on the TOPSIS method. Scientific Papers. Series A. Agronomy LXI(1).

Tigkas D, Vangelis H, Tsakiris G (2012) Drought and climatic change impact on streamflow in small watersheds. Science of The Total Environment 440: 33-41.

Topaloğlu F (2006a) Regional trend detection of Turkish river flows. Nordic Hydrology 37(2): 165-182.

Topaloğlu F (2006b) Trend detection of streamflow variables in Turkey. Fresenius Environmental Bulletin 15(7): 644-653.
Topaloğlu F, Irvem A, Özfidaner M (2012) Re-evaluation of trends in annual streamflows of Turkish rivers for the period 1968-2007. Fresenius Environmental Bulletin 21(8): 2043-2050.

Türkes M (1990) Türkiye'de kurak bölgeler ve önemli kurak yıllar. Doktora Tezi, İstanbul Üniversitesi Deniz Bilimleri ve Coğrafya Enstitüsü.

Türkes M (2002) Spatial and temporal variations in precipitation and aridity index series of Turkey. In: Mediterranean Climate Variability and Trends, Hans- Jürgen Bolle, (ed.), Regional Climate Studies. Springer Verlag, Heidelberg, pp. 181-213.

Türkes M, Tatlı H (2009) Use of the standardized precipitation index (SYI) and modified SPI for shaping the drought probabilities over Turkey. International Journal of Climatology 29: 2270-2282.

Yang T, Chou P (2005) Solving a multiresponse simulationoptimization problem with discrete variables using a multi-attribute decision making method. Mathematics and Computers in Simulation 68: 9-21.

Yoon K, Hwang CL (1985) Manufacturing plant location analysis by multiple attribute decision making, part 1-single-plant strategy. International Journal of Production Research 23: 345-359.

Yürekli K, Anlı AS, Örs İ, Karahan G (2009) Sakarya havzası aylık akımlarının kuraklık analizi. I. Ulusal Kuraklık ve Çölleşme Sempozyumu Bildiriler Kitabı, Toprak ve Su Kaynakları Araştırma Enstitüsü, Konya, s. 779-784. 